\title{
A simulated Model for High Pressure Mercury Lamp Operation by means of State Variable Equations ${ }^{\dagger}$
}

\author{
Sen-ichiro Nakanishi* (Fellow Member) \\ Toyoji Himei* (Fellow Member)
}

\begin{abstract}
Recently, low wattage HID lamps are developed and used steadily for an indoor illumination such as offices or stores. The ballast for the lamps is required to be in smaller size and lighter weight, and moreover it is required to have excellent function with good controllability. If the simulation model of the HID lamps is given for the behavior in transient such as in starting period, it is very useful for analysis and design of the ballast.

In the paper, a simulation model for high pressure mercury lamps is proposed by means of state variable method. The equations are taken account of the state of each portion such as pressure, temperature and mercury vapor density, etc. The coefficient values of the equations are investigated physically and determined referred to experiment. The calculated results are in good agreement with the experimental results. Then, it is verified that the simulation model is available for the high pressure mercury lamps.
\end{abstract}

\section{Introduction}

HID lamps, which have been extensively used for an outdoor illumination due to their features such as point source of light, high output, high luminance and long life, are now used, also, for an indoor illumination such as offices or stores since low wattage HID lamps of several-ten watt class were developed, recently. Depending on the expansion of its application, the ballast for the lamps is required to be in smaller size and lighter weight and moreover it is required to have excellent functions with good controllability. If the simulation model of HID lamps by using equations is given for the behavior in transient such as in dimming period or in starting period, it is very useful for the analysis and design of the operating circuit. As, in HID lamps, the plasma in the light emitting tube operates at a high pressure and at a high temperature, the output change corresponding to the input change will be delayed due to the heat

$\dagger$ This paper is translated from Journal of IEI-J Vol. 71, No. 6 for which IEI-J excellent paper prize was awarded.

* The deceased

** Tsushima Naka 3 chome, Okayama 700 Japan capacity. Furthermore, the change of vaporization of sealed-in substance will give an influence to the V-I characteristic and the light output of the lamp. Therefore, it is desirable to introduce a simulation model which takes these factors into consideration.

Among HID lamps, it is high pressure mercury lamp that has a long history, that is a lamp with a completed technology and that is relatively simple for the lightening operation. Therefore, a number of analyses of lightening operaiton has been reported so far such as; equations describing the relationship among the electric field strength at stable state of the lamp positive column, the input power per unit length, and the effective temperature etc. ${ }^{1) 2}$; a method of expressing the lamp characteristics by equivalent conductance ${ }^{3)-5)}$; a nonlinear dynamic model of lamp terminal V-I characteristic ${ }^{6)}$; a method based on the theory of plasma ${ }^{7)}$, etc. However, these reports could not simulate the transient characteristic in starting period or in dimming period because they did not take account of the change of sealed-in mercury vapor density or of lamp external tube temperature.

Consequently, the authers once proposed a simulation model of high pressure mercury lamp 
by taking account of a change of mercury vapor density and temperature ${ }^{8)}$. The intention of this model was not placed in establishing a strict and theoretical micro-model but in describing a model by a set of equations including voltage, current, temperature and pressure, etc., which were represented, respectively, as a state variable having a sufficiently long time constant compared to the $\mathrm{AC}$ power line frequency together with respective state variable of portions of the circuit. Concerning the operation of lamp positive column, only its arc state was concerned so that it was assumed that the voltage drop of the electrode was constant and only mercury was present here as a sealed-in gas component. By using such a model, it is capable of studying the parameters contributing to the time delay of lamp operation, consequently this model will be useful for the study of shortening the lamp starting time.

In this paper, a simulation model using state variable equations is constructed by analysing the equations of voltage, current, temperature, pressure and mercury vapor density, etc. of a high pressure mercury lamp. In addition, the coefficient values of the equations are calculated physically and determined experimentally. The calculated results by using these coefficient values are in relatively good agreement with the experimental results in transient as well as in stable state. The results obtained is reported in detail in this paper.

\section{Lightening Transient Operation and State Variable}

\subsection{Operating Circuit and Assumption}

An operating circuit of the basic $\mathrm{L}$ ballast of high pressure mercury lamp, which is used for the description in the paper, is shown in Fig. 1. The descriptive drawing of a high pressure mercury lamp, here defined as a lamp with an external tube, is shown in Fig. 2., where. $D_{1}$ is I.D. of light emitting tube, $\mathrm{L}_{\mathrm{a}}$ is inter-electrode distance, $m$ is sealed-in mercury density, $m_{v}$ is vaporized mercury content, $D_{2}$ is I.D. of external tube, $m_{u}\left(=m_{v} / L_{a}\right)$ is mercury density per unit length of positive column, $T_{p}$ is effective temperature of positive column ${ }^{2)}, T_{w}$ is wall temperature of positive column, $T_{b}$ is wall temperature of light emitting tube and $T_{c}$ is ambient temperature of lamp.

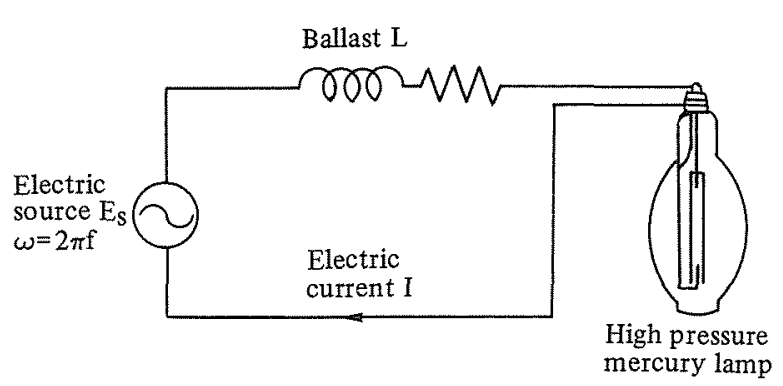

Fig. 1 Operating circuit of high pressure mercury lamp with $L$ ballast

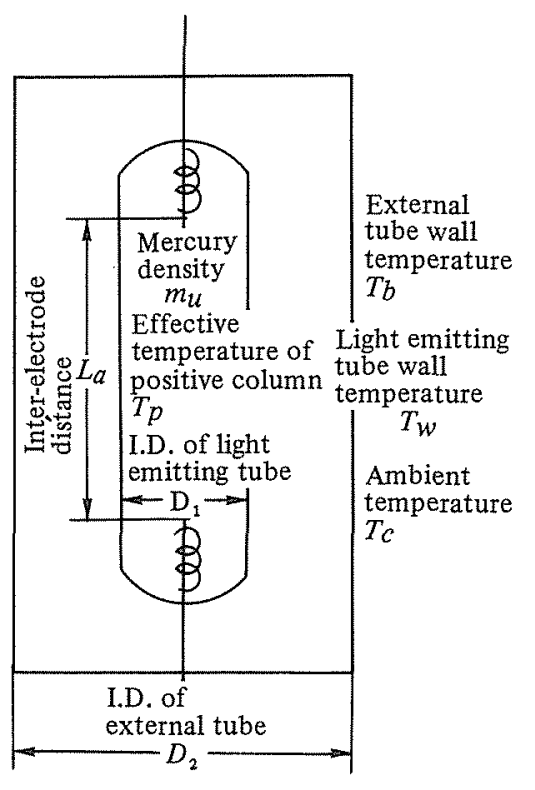

Fig. 2 Descriptive drawing of high pressure mercury lamp

Concerning the above-mentioned operating cirucit and the lamp, the following conditions were assumed.

(1) The operating state of the lamp to be discussed is the state after the starting of the lamp, i.e., the state after the completion of the transfer from the glow discharge to the arc discharge.

(2) While the lamp is operated under the local heat ballance, the calculation is performed by using an equivalent voltage, current and temperature, etc. obtainable when observed as an integral system. 
(3) The change of temperature and pressure in the lamp is rather slow compared to the period of angular frequency of $\mathrm{AC}$ power source voltage. That is, the temperature and pressure change depending on the effective value of voltage and current, or depending on the mean value of power.

(4) The electrode voltage drop of is constant.

(5) The sealed-in gas component is only mercury, wherein an influence of $\mathrm{Ne}$ or $\mathrm{Ar}$ is neglected.

\subsection{Lightening Transient Operation}

First of all, in order to derive a mathematical simulation model in the circuit of Fig. 1, a lightening transient operation, in the starting period or after the source voltage etc. was changed for dimming, should be observed. Obviously, the following approach is applicable to an operating circuit provided with another different ballast.

A lamp shows a V-I characteristic corresponding to a particular mercury vapor pressure. Therefore, the voltage and current of the lamp are determined by the level of source voltage and the impedance of the ballast. The power of such voltage and current are supplied into the lamp positive column, at last being converted into light and heat. If the power energy supplied into the lamp is equal to the energy of light and heat escaping from the lamp, the lamp is operating in a stable state. However, if the input energy is not equal to the output energy, the lamp temperature and the mercury vapor pressure change accordingly and the V-I characteristic of the lamp also changes, consequently. The above-mentioned change continues until a stable state of operation is attained by a balance of input and output energy. Fig. 3 shows a summary of a lightening operation.

\subsection{State Variable}

As variables for expressing the operating state of high pressure mercury lamp by equations, state variables are introduced, while a state variable is being advantageously used in the modern control theory of automatic control. The state variables are a number of variables which can determine the dynamic state of a system. In this case, for the state variables of high pressure mer-

(1)

tch on/Change voltage etc. in starting (in dimming period) period)

(2) V-I characteristic corresponding to given atm. pressure is determined.

(3)

(3) Voltage and current of lamp are determined by source coltage, impedance and lamp characteristic.

(4)

(5) in to positive column.

Power is converted into light and heat.

(6) Is input power balanced to lamp output of light and heat energy?

(9)

\begin{tabular}{|l|l|}
\multicolumn{1}{c|}{} & YES \\
\hline $\begin{array}{l}\text { Stable } \\
\text { operation }\end{array}$ \\
\hline
\end{tabular}

Fig. 3 Summary of lightening transient operation of high pressure mercury lamp

Table 1 State variable of high pressure mercury lamp

\begin{tabular}{l|c|c}
\multicolumn{1}{c|}{ State variable } & Symbol & Unit \\
\hline Lamp voltage & $V_{\text {lamp }}$ & $\mathrm{V}$ \\
\hline Lamp current (circuit current) & $\mathrm{I}$ & $\mathrm{A}$ \\
\hline Lamp power & $\mathrm{P}_{\text {lamp }}$ & $\mathrm{W}$ \\
\hline $\begin{array}{l}\text { Voltage per unit length of positive } \\
\text { column }\end{array}$ & $V_{u}$ & $\mathrm{~V} / \mathrm{cm}$ \\
\hline $\begin{array}{l}\text { Power per unit length of positive } \\
\text { column }\end{array}$ & $P_{u}$ & $\mathrm{~W} / \mathrm{cm}$ \\
\hline $\begin{array}{l}\text { Effective temperature of positive } \\
\text { column }\end{array}$ & $T_{p}$ & $\mathrm{~K}$ \\
\hline $\begin{array}{l}\text { Mercury content (sealed-in) } \\
\text { Mercury vapor density per unit length } \\
\text { of positive column }\end{array}$ & $m_{u}$ & $\mathrm{mg} / \mathrm{cm}$ \\
\hline $\begin{array}{l}\text { Light emitting tube wall temperature } \\
\text { Lamp external tube wall temperature }\end{array}$ & $T_{W}$ & $\mathrm{~K}$ \\
\hline $\begin{array}{l}\text { Mercury vapor pressure within } \\
\text { light emitting tube }\end{array}$ & $T_{b}$ & $\mathrm{~K}$ \\
\hline \begin{tabular}{l} 
Electrode voltage drop \\
\hline
\end{tabular} & $P_{e l}$ & $\mathrm{mmHg}$ \\
\hline
\end{tabular}

Note) The value of voltage and current is effective value and the value of power is the mean value for 1 cycle.

cury lamp are selected inter-terminal voltage, current and power, electrode voltage drop, voltage and power per unit length of positive column; effective temperature of plasma relating to thermal characteristic; wall temperature of light emitting tube, wall temperature of external tube, and mercury vapor pressure and mercury vapor content per unit length of positive 
column. Symbols and units of these state variables are shown in Table 1.

\section{State Equation Model}

\subsection{State Equation}

A simulation model by state equations of high pressure mercury lamp is derived by using the state variables defined in Chapter 2 . In the present operating circuit, the input variable is the source voltage. And the state equation is nonlinear.

At first, an equation of voltage, current and mercury vapor pressure, etc. is obtained (see Fig. 3). From Fig. 6. 18 of reference (2), a relation of voltage per unit length of light emitting tube of lamp $V_{u}(\mathrm{~V})$ with current I(A), mercury vapor pressure $P_{r}(\mathrm{mmHg})$ and tube diameter $D_{1}$ $(\mathrm{cm})$ can be approximated by the equation (1).

$$
\left.\begin{array}{l}
V_{u}=D_{1}{ }^{-0.3219}\left\{\frac{P r}{(\log (I)+1.3834)^{4.013}}\right\}^{k} \\
K=0.16112 \log \frac{10^{4} I}{8.552}
\end{array}\right\} \ldots
$$

The power of high pressure mercury lamp $F$ lamp can be obtained from lamp voltage $V$ lamp and current I by the equation (2), where $\cos \phi$ is lamp power factor of the high pressure mercury lamp.

$$
P_{\text {lamp }}=V_{\text {lamp }} I \cos \phi \ldots \ldots \ldots \ldots \ldots
$$

Assuming that the lamp power is equal to the sum of the power of positive column and the electrode loss $P_{\mathrm{el}}$, the lamp power $P_{\text {lam }}$ can be obtained from the equation (3),

$$
\begin{aligned}
P_{\mathrm{lamp}} & =L_{a} P_{y}+P_{e l}=L_{a} V_{u} I P F_{a}+V_{e l I} \ldots \\
P_{u} & =V_{u} I P F_{a} \ldots \ldots \ldots \ldots \ldots \ldots
\end{aligned}
$$

where $V_{e l}$ is electrode voltage drop ${ }^{9)}$ and $P F_{\mathrm{a}}$ is power factor of positive column, i.e. the power factor resulted by the distortion generated by the nonlinearity of the positive volumn. From equation (2) and (3), the effective value of terminal voltage of high pressure mercury lamp, $V$ lamp can be obtained as shown in the equation (5),
$V_{\text {lamp }} \cos \phi=L_{a} V_{u} P F_{a}+V_{e e}$

$V_{\text {lamp }}=\frac{L_{a} V_{u} P F_{a}+V_{e l}}{\cos \phi} \ldots \ldots \ldots \ldots$

where $V_{\text {lamp }} \cdot \cos \phi$ is active component of lamp voltage $V_{\text {lamp }}$. The reactive component $V_{\text {lamp }}$. $\sin \phi$ can be expressed as a 3-dimensional vector by dividing the reactive component into a phase difference component and a distortion component ${ }^{10)}$. When only the distortion component is taken into consideration for $V_{\text {lamp }} \cdot \sin \phi$ by approximating the phase difference component to zero since it is rather small compared to the waveform of lamp voltage and current, a circuit equation in the operating circuit diagram of Fig. 1 can be expressed as shown in equation (6), where the distortion component is included as a third component.

$E_{s}^{2}=(w L I)^{2}+\left(V_{\text {lamp }} \cos \phi+r I\right)^{2}+\left(V_{\text {lamp }} \sin \phi\right)^{2}$ $\ldots \ldots(6)$

As described in the above, if the vapor pressure $P_{\mathrm{r}}$ is given, the lamp voltage $V_{\text {lam }}$ and current I are determined from the equation (1), (2), (6) (see Fig. 3(3)).

Then, an energy input/output in the radial direction of positive column will be discussed. It is assumed that the loss in the axial direction of positive column is in balance with the power consumption. From the balance of input/output energy, the equation (7) is established in a stable state $^{2)}$,

$$
P_{u}=P_{u r d}+P_{u c} \ldots \ldots \ldots \ldots \ldots
$$

where $P_{u}(\mathrm{~W} / \mathrm{cm}), P_{u r d}(\mathrm{~W} / \mathrm{cm})$ and $P_{u c}(\mathrm{~W} / \mathrm{cm})$ are input power, light output and conduction loss, respectively, per unit length of positive column. However, in transient, on the other hand, an accumulated energy of positive column changes so that the accumulated energy $P_{u s}(\mathrm{~W} /$ $\mathrm{cm}$ ) has a value, thereby $P_{u}$ being determined as shown in the equation (8).

$$
P_{u}=P_{u r d}+P_{u c}+P_{u s} \ldots \ldots \ldots \ldots
$$

The input power per unit length of positive 
column $P_{u}$ can be obtained from the equation (3) (equation (9)).

$$
P_{u}=\frac{P_{\text {lamp }}-P_{e l}}{L_{a}}
$$

The light output per unit length of positive column $P_{\text {urd }}$ can be expressed by average exciting voltage $V_{e x}$ and effective temperature of positive column $T_{p}$ as shown in the equation $(10)^{1)}$.

$P_{u r d}=m_{u} G_{1} \epsilon-e^{V_{e x} /\left(K_{b} T_{p}\right)} \ldots \ldots \ldots$

where $m_{u}$ is mercury content per unit length of positive column $(\mathrm{mg} / \mathrm{cm}), G_{1}$ is equal to $\gamma C_{1}$ of the equation (6.21) in page 169 of reference (1), which is a coefficient of light output, $e$ is charge of an electron and $K_{b}$ is Boltzmann's constant which is obtained from $e \cdot V_{e x} / K_{b}=90500(\mathrm{~K})^{2)}$. The conduction loss can be obtained from the equation $(11)^{6)}$,

$$
P_{u c}=\pi m_{u} H_{1} D_{1}\left(T_{p}-T_{w}\right) \ldots \ldots \ldots
$$

where $H_{1}(\mathrm{~W} / \mathrm{cm} \cdot \mathrm{mg} \cdot \mathrm{K})$ is heat transfer coefficient of mercury vapor divided by mercury mass. In page 138 of reference (2), $m_{u}$ is not included because it is an equation of steady state. It was found from the calculation and experiment that in transient it is better to take account of the change of $m_{u}$. The accumulated energy per unit length of positive column can be obtained from the equation (12),

$$
P_{u s}=m_{u} C_{1} \frac{d T_{p}}{d t} \ldots \ldots \ldots \ldots
$$

where $C_{1}$ is specific heat of mercury vapor.

By summarizing the above-mentioned equations, equation (13) can be obtained,

$$
\begin{aligned}
& m_{u} \mathrm{C}_{1} \frac{d T_{p}}{d t}+4 \pi H_{1}\left(T_{p}-T_{w}\right)+m_{u} G_{1} \mathrm{EXP} \\
& \frac{-90500}{T_{p}}=P_{u} \ldots \ldots \ldots \ldots \ldots \ldots \ldots
\end{aligned}
$$

where the relation between input power and positive column temperature can be expressed by a nonlinear differential equation. In a state without temperature change, i.e. in a stable state, the following result is obtained

$$
P_{u s}=m_{u} \cdot C_{1} \cdot\left(d T_{p} / d t\right)=0
$$

so that by substituting it into the equation (13) the relation of effective temperature of positive column $T_{p}$ with the input power $P_{u}$ can be given by the equation $(14)^{1)}$,

$$
T_{p}=\frac{90500}{17.0-I_{n} \frac{P_{u}-P_{u c}}{m_{u}}}
$$

where the value $\ln \left(G_{1}\right)=17.0$ given by Elenbaas is used ${ }^{1)}$.

On the other hand, the relation of the voltage per unit length of positive column with the input power in a stable state is given by the equation (15).

$V_{u}=\frac{6 P_{u}^{1 / 2} m_{u}^{7 / 12}}{\left(P_{u}-4.5 P_{u}^{1 / 4}\right)^{1 / 3} D^{3 / 2}} \cdots \cdots$

By plotting in a diagram the relation of $V_{\text {lamp }}$ and I by means of the equation (3), (4), (5) and (15), V-I characteristic curve in a stable operating state can be obtained ${ }^{18)}$.

The conduction loss $P_{u c}$ is transmitted from the wall of light emitting tube to the external tube. Since the difference of average temperature $T_{w}$ and $T_{b}$ (see Fig. 2) results in heat accumulation and the difference is proportional to the rate-of-change of the energy emitted from the external wall. This relation can be expressed by the differential equation (16),

$\mathrm{C}_{2} \frac{d T_{w}}{d t}+\pi H_{2} D_{2}\left(T_{w}-T_{b}\right)=P_{u c} \ldots$

where $C_{2}$ is heat capacity per unit length of light emitting tube wall (including the sealed-in gas between light emitting tube and external tube), $H_{2}$ is thermal conductivity and $\pi D_{2}$ is surface area per unit length of external tube.

For the external tube wall, an equation (17) similar to the above can be obtained,

$$
\begin{aligned}
& C_{3} \frac{d T_{p}}{d t}+\pi D_{2} H_{3}\left(T_{b}-T_{c}\right)= \\
& \pi H_{2} D_{2}\left(T_{w}-T b\right) \ldots \ldots
\end{aligned}
$$

where $C_{3}$ is heat capacity and $\mathrm{H}_{3}$ is heat transfer 
coefficient of external tube wall. As shown later in an example of numerical calculation, after the starting of lamp, the effective temperature of plasma of mercury lamp is raised rapidly, finally reaching to about $5000 \mathrm{~K}-6000 \mathrm{~K}$. Contrarily, the tube wall temperature is raised gradually without a rapid change, finally attaining about $1000 \mathrm{~K}$ in a steady state. As the sealed-in mercury content of mercury lamp is at most several$10 \mathrm{mg}$, the mercury vapor density is changed in a time lag with the change of tube wall temperature (see the equation (20)). It is assumed that the mercury vapor makes an operation usually in an unsaturated state. Now, it is assumed that the relation of the mercury vapor pressure within light emitting tube $P_{r}(\mathrm{mmHg})$ with the effective temperature of positive column $T_{p}$ can be expressed by the equation (19) derived by multiplying the van der Waals' equation (18) by the square of tube wall temperature $T_{w}$ and introducing the coefficient $K_{1}$, where the number of gram moles $\mathrm{n}$ is represented by mercury vapor density per unit length of positive column $m_{u}$ $(\mathrm{mg} / \mathrm{cm})$.

$$
\begin{aligned}
(P & \left.+\frac{n^{2} a}{V^{2}}\right)(V-n b)=n R T \ldots \ldots \ldots \\
P_{r} & =K_{1}\left\{\frac{m_{u} L_{a} R T_{p}}{1000 \times 200.59 V-b m_{u} L_{a}}\right. \\
& \left.-a\left(\frac{m_{u} L_{a}}{1000 \times 200.50 V}\right)^{2}\right\} T_{w}{ }^{2} \ldots \ldots
\end{aligned}
$$

In the equation (18), $P$ is pressure (atm), $\mathrm{T}$ is temperature $(\mathrm{K}), \mathrm{n}$ is number of gram moles, $\mathrm{V}$ is volume $\left(\mathrm{cm}^{3}\right), R$ is molecular gas constant $\left(\mathrm{R}=82.057 \mathrm{~cm}^{3} \cdot \mathrm{atm} / \mathrm{mole} \cdot \mathrm{K}\right.$ and $a, b$ is constant $\quad\left(\mathrm{a}=8.09 \times 10^{6} \mathrm{~cm}^{3} \cdot \mathrm{atm} / \mathrm{mole}^{2}, b=\right.$ $17.00 \mathrm{~cm}^{3} /$ mole) $)^{11)}$. And, in the equation (19), 200.59 is the number of gram moles of mercury. If the tube wall temperature raised to the 1st power is used, the characteristic of the calculated value and the experimental value of light output $R_{d}$ is different therebetween so that the tube wall temperature raised to the 2nd power was used due to a relatively good agreement therebetween.

It can be presumed that the mercury vapor density of positive column is increased by the fact that the unvaporized remaining mercury is vaporized by the heat received from the plasma and the light emitting tube wall. Assuming from the pattern of the experimental results, that the mercury density responds to the light emitting tube wall temperature in the second order lag, the relation therebetween is expressed by the equation (20).

$\frac{d^{2} m_{u}}{d_{t}^{2}}+2 \delta w_{n} \frac{d m_{u}}{d t}+w_{n}^{2} m_{u}=\left(T_{w}-273\right) / B_{1}$

However, $m_{u} \leqq m / L_{a}$ because the mercury vapor density can never exceed the sealed-in total mer cury content. It is supposed that the reason of the second order lag of mercury is caused by the following reasons. While it has been supposed so far that the mercury is being attached to the light emitting tube wall near the arc, it can be assumed that it is actually attached to the end portion of the lgiht emitting tube. Therefore, due to the lag of heat transfer from the side of the light emitting tube wall to the end portion thereof the vaporization of mercury is delayed. As it is assumed that until a complete vaporization of mercury this lag mainly allows the lamp voltage to change, the equation (20) showing the response of second order lag was proposed from the behavior of the change of lamp voltage. As the equation (20) is a second order differential equation, its response characteristic is determined, as obviously from the automatic control etc., by damping factor $\delta$ and eigen angular frequency $w_{n}$. And, between $\delta$ and $w_{n}$ there exists the relation of the equation (21),

$$
w_{n}=\frac{\pi}{\left(1-\delta^{2}\right)^{1 / 2} T_{0}} \quad \ldots \ldots \ldots \ldots \ldots
$$

where $T_{0}$ is period of eigen angular frequency.

As shown in the above, the state equations (1), (2), (3), (4), (6), (9), (11), (13), (16), (17), (19), (20) are 12 simultaneous equations and the variables are 12 state variables as shown in Clause 2.3 so that the state of lamp can be determined and calculated by these equations. That is, these equations themselves are the mathematical simulation model.

\subsection{Discussion of Constant Value}

For a 100W high pressure mercury lamp, the values of coefficients were determined by making them correspond to the physical state of the lamp as shown in the following. The electric properties of lamp circuit and the geometrical 
constant values are summarized in Table 2 .

Table 2 Constant value

\begin{tabular}{l|c}
\hline \multicolumn{1}{c|}{ High pressure mercury lamp } & HF 100 \\
\hline Effective value of source voltage (rating) & $200 \mathrm{~V}$ \\
\hline Source angular frequency $\omega(\mathrm{f}=60 \mathrm{~Hz})$ & 377 \\
\hline Impedance $\mathrm{L}$ (including source impedance) & $0.382 \mathrm{H}$ \\
\hline Resistance $\mathrm{r}$ (including iron loss) & $14 \Omega$ \\
\hline Power factor of lamp cos $\phi$ & 0.83 \\
\hline Power factor of positive column $\mathrm{PFa}$ & 0.81 \\
\hline Length of positive column La & $3 \mathrm{~cm}$ \\
\hline I.D, of internal tube $\mathrm{D}_{1}$ & $0.8 \mathrm{~cm}$ \\
\hline I.D, of external tube $\mathrm{D}_{2}$ & $5.5 \mathrm{~cm}$ \\
\hline Electrode voltage drop $\mathrm{V}_{\mathrm{el}}$ & $15 \mathrm{~V}$ \\
\hline Mercury content & $9.1 \mathrm{mg}$ \\
\hline
\end{tabular}

(1) Determination of $B_{1}$

In a steady state, the differential terms of the equation (20) are eliminated therefrom, $B_{1}$ can be determined as shown in the equation (22) since the total vaporization temperaiure of sealed-in mercury $T_{w s}$ is assumed as $930 \mathrm{~K}$ from the experience (see Table 2 ).

$$
B_{1}=\frac{T_{w s}-273}{w_{n}^{2} m_{u}}=5000 \ldots \ldots \ldots
$$

The value of $w_{n}$ will be described later.

(2) Determination of $C_{1}, C_{2}, C_{3}$

$C_{1}$ is specific heat of mercury vapor at positive column. If $C_{1}=0.0001344 \mathrm{~W} \cdot \mathrm{sec} / \mathrm{mg} \cdot \mathrm{K}$ (converted from $C_{1}=0.032 \mathrm{cal} / \mathrm{deg} \cdot \mathrm{g}\left(200^{\circ} \mathrm{C}\right.$ ) from the Physical Property Table) is used for calculation, the temperature and pressure diverge in oscillating. However, at $C_{1}=0.03$ it happened to come into a good agreement so that $C_{1}=0.03$ was selected. $C_{2}$ is heat capacity per unit length of light emitting tube wall. Also, in this case, a value, $C_{2}=0.03$, different from the value in the Physical Property Table $\left(C_{2}=\right.$ $0.34 \mathrm{~W} \cdot \mathrm{sec} / \mathrm{K} \cdot \mathrm{cm}$ obtained from the specific heat of glass $(0.63 \mathrm{~W} \cdot \mathrm{sec} / \mathrm{g} \cdot \mathrm{deg}=0.15 \mathrm{cal} / \mathrm{g} \cdot \mathrm{deg})$ multiplied by the weight per unit length of light emitting tube) was selected from the point of agreement between the calculated value and the experimental value. $C_{3}$ is heat capacity per unit length of external tube. $C_{3}=2.33 \mathrm{~W} \cdot \mathrm{sec} / \mathrm{K} \cdot \mathrm{cm}$ is obtainable from the Table. However, $C_{3}=$ $2 \mathrm{~W} \cdot \mathrm{sec} / \mathrm{K} \cdot \mathrm{cm}$ was selected by taking account of the sealed-in gas between the light emitting tube and external tube (specific heat of gas being assumed to be small).

(3) Determination of $G_{1}$

As obvious from the equation (10), it is coefficient of light output in Saha's equation. It is expressed as $G_{1}=\epsilon^{\mathrm{c}}$ by using $\mathrm{C}(\mathrm{W} / \mathrm{mg})$ in p.158 of reference (2). $G_{1}=2.42 \times 10^{7}$ is obtained.

(4) Determination of $H_{1}, H_{2}, H_{3}$

They are coefficients relating to heat transfer. Here, they were selected from the values in a stable operation. $H_{1}$ can be obtained from the equation (11) by substituting $T_{p} \fallingdotseq 6000 \mathrm{~K}$ (the value abtained by substituting $C-17, P^{\prime}=30$, $m^{\prime}=3.04$ into the equation (6.26) in p.158 of reference (2)), $T_{w} \fallingdotseq 1000 \mathrm{~K}, P_{u c} \fallingdotseq 10 \mathrm{~W}, m_{u}=$ $3.01 \mathrm{mg} / \mathrm{cm}, D_{1}=0.8 \mathrm{~cm}^{6)}$ as shown in the equation (23).

$H_{1} \fallingdotseq \frac{P_{u c}}{\pi m_{u} D_{1}\left(T_{p}-T_{w}\right)}=0.0002852 \ldots$

From an agreement of calculation and experiment, 0.00075 was selected for $H_{1} \cdot H_{2}$ and $H_{3}$ can be obtained in the same way.

(5) Determination of $K_{1}$

From the comparison of experimental value and calculation value, $K_{1}=3.05 \times 10^{-7} \mathrm{~K}^{-2}$ was selected.

(6) Determination of $\delta, \omega_{\mathrm{n}}, T_{0}$

$\delta$ is damping factor. By comparing the waveform of a normalized 2nd order differential equation (Elect. Eng. Handbook, p.364, Fig. 6) and Fig. 6 shown later, $\delta=0.8$ was selected. $T_{0}$ is period of eigen angular frequency. By taking into consideration the value obtained by multiplying the rising time (about 40sec) of transient state of light output, which is obtained from the actual measurement of Fig. 6 shown later, by $\left(1-\delta^{2}\right)^{0.5}=0.6, T_{0}=25 \mathrm{sec}$ was selected. $\omega_{\mathrm{n}}$ can be obtained by sustituting the values of $\delta$ and $T_{0}$ into the equation (21).

Respective coefficient obtained in such a way described in the above is summarized in Table 3.

\subsection{Comparison of Calculation Value and Experimental Value}

Fig. 4 shows a stable operating state and an operation when the source voltage was changed. In this figure, the broken line shows the droop- 
Table 3 Coefficient value

\begin{tabular}{c|l|l|c}
\hline $\begin{array}{c}\text { Coef- } \\
\text { ficient }\end{array}$ & Value & \multicolumn{1}{|c}{ Unit } & $\begin{array}{c}\text { Reference } \\
\text { equation }\end{array}$ \\
\hline$B_{1}$ & 5000 & $\mathrm{mg} / \mathrm{sec}^{2} \cdot \mathrm{K}$ & 20 \\
\hline$C_{1}$ & 0.03 & $\mathrm{~W} \cdot \mathrm{sec} / \mathrm{mg} \cdot \mathrm{K}$ & 12 \\
\hline$C_{2}$ & 0.03 & $\mathrm{~W} \cdot \mathrm{sec} / \mathrm{cm} \cdot \mathrm{K}$ & 16 \\
\hline$C_{3}$ & 2 & $\mathrm{~W} \cdot \mathrm{sec} / \mathrm{cm} \cdot \mathrm{K}$ & 17 \\
\hline$G_{1}$ & $2.42 \times 10^{7}$ & $\mathrm{~W} / \mathrm{mg}$ & 10 \\
\hline$H_{1}$ & 0.000775 & $\mathrm{~W} / \mathrm{cm} \cdot \mathrm{mg} \cdot \mathrm{K}$ & 11 \\
\hline$H_{2}$ & 0.007848 & $\mathrm{~W} / \mathrm{cm} \cdot \mathrm{K}$ & 16 \\
\hline$H_{3}$ & 0.00289 & $\mathrm{~W} / \mathrm{cm} \cdot \mathrm{K}$ & 17 \\
\hline$K_{1}$ & $3.05 \times 10^{-7}$ & $1 / \mathrm{K}^{2}$ & 19 \\
\hline$\delta$ & 0.8 & $\mathrm{Non} \cdot \mathrm{dim}$ ension & 20 \\
\hline$\omega_{n}$ & 0.209 & $\mathrm{rad} / \mathrm{sec}$ & 20 \\
\hline$T_{0}$ & 25 & $\mathrm{sec}$ & 21 \\
\hline
\end{tabular}

ing characteristic line of the source side viewed from both ends of lamp which was calculated by taking acount of the equation (6), the thin solid lines $\mathrm{B}, \mathrm{D}$ showing V-I curve at constant mercury vapor pressure which was calculated from the equations (1), (5) and thick solid lines $\mathrm{A}, \mathrm{C}$ showing V-I curve in a stable operation when the input and output energy, calculated by using the equation (6.26) in p.171 of reference (1), are balanced. The mark $\bigcirc$ denotes the actual measurement. From the figure, it is understood that both values are in good agreement.

Next, the operation at a rapid change of source voltage $E_{s}$ is described. Even at a rapid change (drop) of voltage, the mercury vapor pressure can not change rapidly together but the operating point displaces from the point $A$ to the point $\mathrm{B}$. Then, the lamp voltage rises irrespective of the dropping of the source voltage. However, since the point $B$ is not a stable operating point, the point $\mathrm{B}$ moves along the curve $\mathrm{B}-\mathrm{C}$ for arriving at the point $\mathrm{C}$ where it is stable. Conversely, at a change (rise) of source voltage from $165 \mathrm{~V}$ to $200 \mathrm{~V}$, the operating point displaces from the point $C$ to the point $D$ and then gradually moves to the point A. While such an operation was explained qualitatively by Nishimura et al. ${ }^{12)}$, in this report an operating characteristic in the case of no change of mercury vapor pressure could be explaned quantitatively, as shown in the calculation results of Fig. 5(b).
Fig. 5(a), (b) is a simulation result of lightening transient operation in a starting period of lamp after switched on, in a change of source voltage from $200 \mathrm{~V}$ to $165 \mathrm{~V}$ and in a reversal change of source voltage. In a starting period, the plasma temperature rises to about $5500 \mathrm{~K}$ or above due to the light output calculated by the equation (10). Furthermore, it is understood that, while the plasma temperature rises rapidly, the change of tube wall temperature and mercury vapor pressure is rather delayed. After having reached to a stable state, a quick response to the change of source voltage is noticable because even at a change of source voltage the temperature change of arc column and arc tube wall is smaller than in a starting period and no change is observed, as obviously from Fig. 5(b).

Fig. 6 is an actual measurement result in a starting period. Except a little longer time constant than in Fig. 5 at the beginning of the starting period (it is assumed that the response of light output is influenced by $T_{w}$ in addition to $\delta, \mathrm{T}_{0}$ ), the calculation results and the measurement results agree qualitatively to a high extent. Also, in a period of the change of source voltage, both results found a relatively good accord ${ }^{18)}$. It can be said from the above results that a simulation model using state equations is appreciatable.

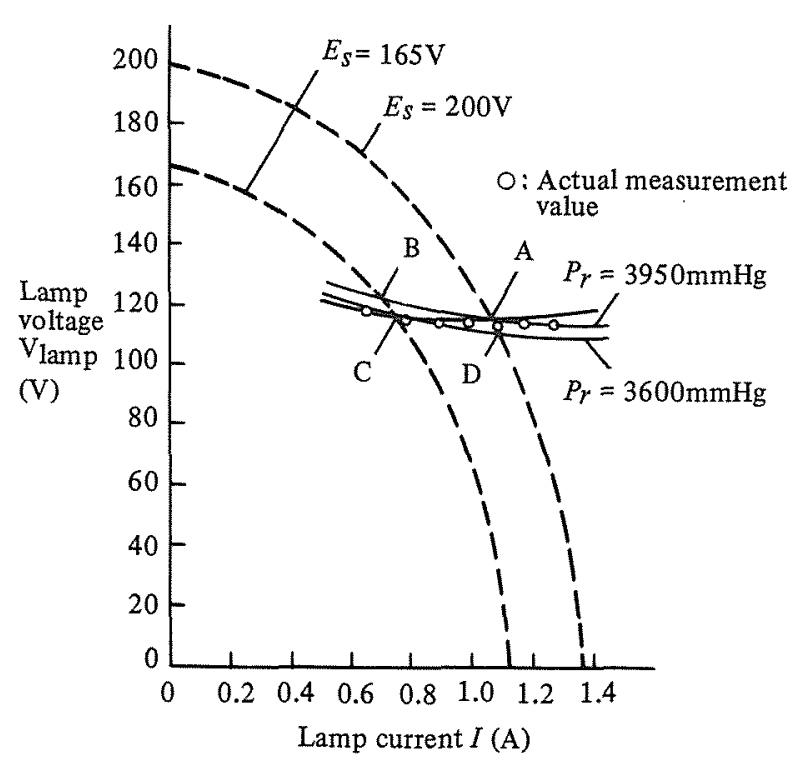

Fig. 4 Lightening operation of lamp viewed from the point of V-I characteristic 


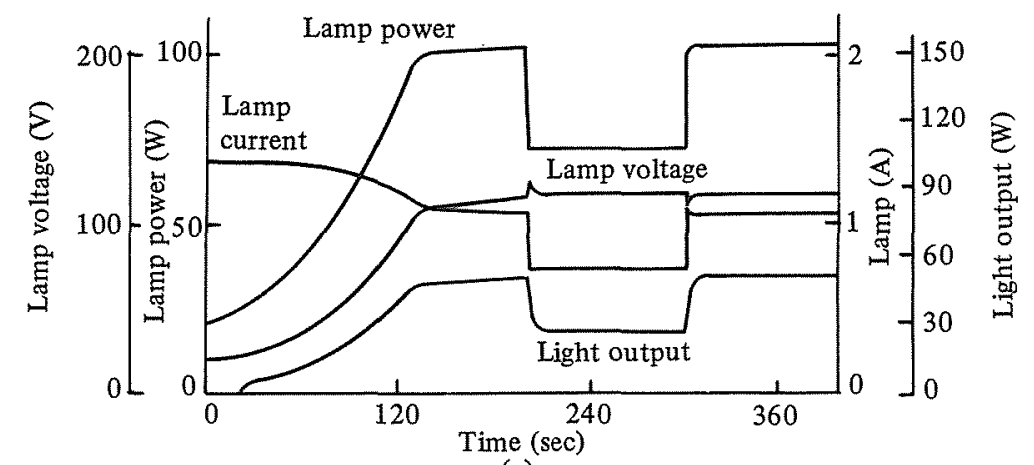

(a)

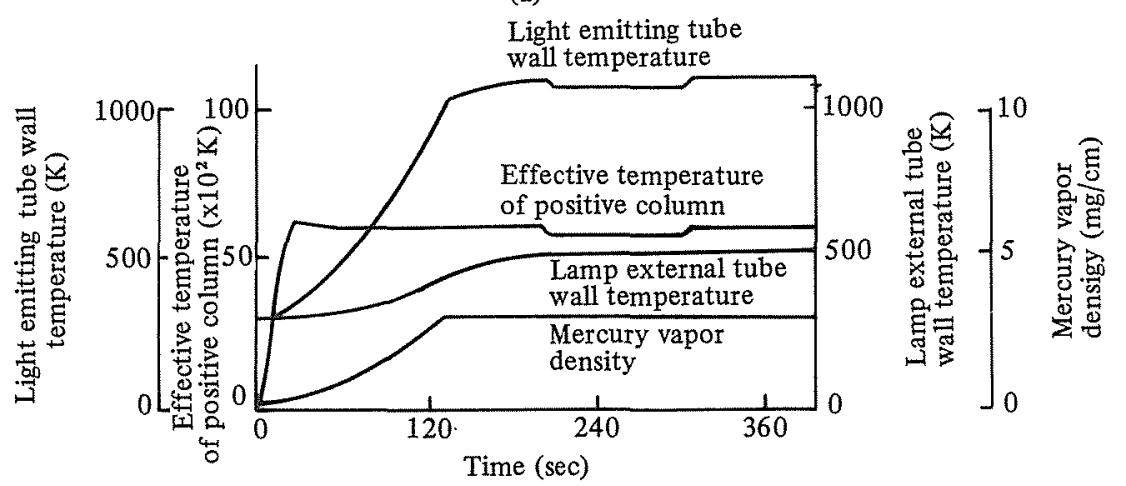

(b)

Fig. 5 Simulation result of lightening transient operation

(a) Voltage, current, power and emission output of lamp

(b) Temperature of each part

\section{Conclusion}

In this paper, a dynamic model to be capable of simulating a transient state of the lightening operation of a high pressure mercury lamp was constructed by using state variable equations,

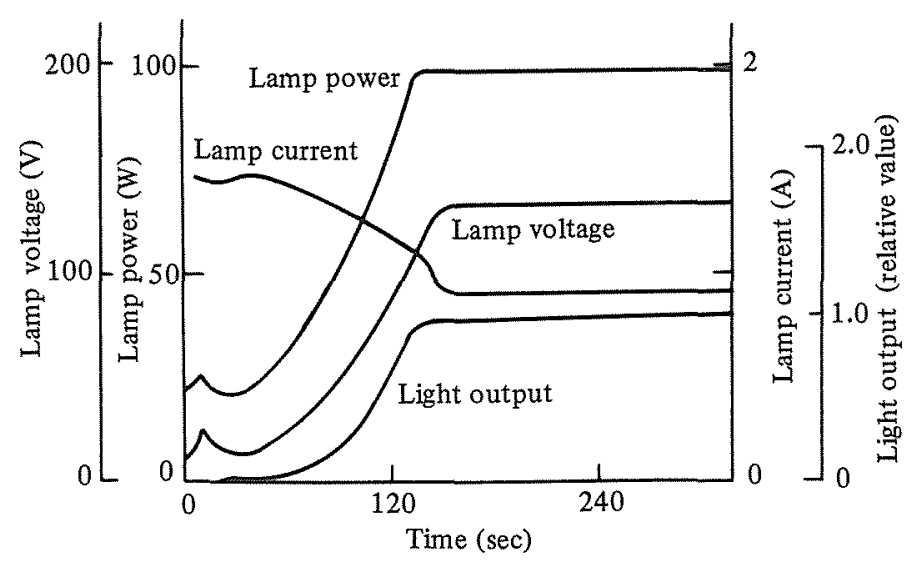

Fig. 6 Actual measurement result in a starting period and the coefficient values of these equations were obtained by an investigation. The calculated results and the experimental results were in relatively good agreement and an appropriateness of the proposed model was verified. The results obtained in this study are summarized as follows.

(1) The relation of electric field strength, current and pressure of lamp positive column was expressed by equations from experimental data;

(2) The pressure of positive column was obtained as an equation of effective temperature of plasma, light emitting tube wall temperature and mercury vapor density;

(3) The relation between mercury vapor density and light emitting tube wall temperature was expressed by a second order differential equation under an assumption of having a second order lag; 
(4) The operating state of the lamp such as voltage, current, temperature, pressure and mercury vapor density, etc. was expressed by 12 state variables and a simulation model was constructed as simultaneous nonlinear state variable equations; and

(5) The calculated results obtained by using coefficient values derived physically and experimentally from the calculation and experiment by an investigation was in relatively good agreement with the experimental results, thereby an appropriateness of the model having been appreciated.

It is expectable that from this model the discussion of characteristics of lamp in a starting period and in a dimming operation and of optimization of circuit constants and lamp parameters will be possible. However, the following items will be taken as a future task for study.

(1) A physical study of equation relating to pressure, temperature and mercury vapor density;

(2) A physical study of equation relating to mercury vapor density and tube wall temperature;

(3) A study of the improvement of lamp starting time in a simulation by using this model; and

(4) An extension of this model to other HID lamps.

Lastly, the authers wish to thank Mr. Komatsubara (technical official of Okayama University) for his advise in the discussion of this study and the Master and Doctor class students of Okayama University for the assistance of the study in the experiment, calcula- tion and the arrangement of data.

\section{References}

(1) Waymouth, J.F.: Electric Discharge Lamps High Pressure Mercury Lamps, The MIT Press, Cambridge (1971)

(2) Elenbaas, W.: "Light Sources", MacMillan' London (1972)

(3) K. Masumi and H. Boh: "Equivalent Conductance Model of Discharge Lamp", J. Illum. Engng. Inst. Jpn. 57-6 (1973) 341

(4) S. Ozaki, T. Inoue and H. Boh: "Calculation of Luminous Flux of Discharge Lamp by Equivalent Conductance Model", J. Erec. Engng. Inst. Jpn. A, 106-1 (1986) 1

(5) Ozaki, Katayama and Noh: "Equation Model of Discharge Lamp by Taking Account of Plasma Temperature Distribution", J. Illum. Engng. Inst. Jpn. 67.2 (1983) 49

(6) Laskowski, E.L., Donoghue, J.F.: A Model of a Mercury Arc Lamp's Terminal V-I behavior, IEEE Trans, Ind, Appl. IA-17-4 (1981) 419

(7) R. Itaya: "Numerical Analysis of Characteristic of Discharge Lamp", Gen. Session of Illum. Engng. Inst. Jpn. (1986) 2

(8) S. Nakanishi and T. Himei: "Characteristic Equation of High Pressure Mercury Lamp", Gen. Session of Illum. Engng. Inst. Jpn. (1986) 28

(9) Springer, R.H. and Lake, W.H.: "Thermal balance of HID electeodes", J. Illum. Engng. Soc. 13-3 (1984) 304

(10) IEEE, IEEE Standard Dictionary of Electrical and Electronics Terms (1971), p. 433-436

(11) Moore W.J., "New Physical Chemistry (A)" (Translation), Tokyo Kagaku Dojin (1967) 19

(12) Nishimura, Nagase, Shiomi and Nagano: "Electronic Ballast for Color Rendering Type High Pressure Sodium Lamp", Tech. J. Matsushita Elec., No.31 (1985) 7

Received September 21, 1990; accepted October 23. 